\title{
BMJ Open Impact of cardiovascular risk factors and medication use on the efficacy of remote ischaemic conditioning: post hoc subgroup analysis of a randomised controlled trial
}

\author{
Astrid Drivsholm Sloth, ${ }^{1}$ Michael Rahbek Schmidt, ${ }^{1}$ Kim Munk, ${ }^{1}$ Morten Schmidt, ${ }^{2}$ \\ Lars Pedersen, ${ }^{2}$ Henrik Toft Sørensen, ${ }^{2}$ Hans Erik Bøtker, ${ }^{1}$ CONDI Investigators
}

To cite: Sloth $A D$,

Schmidt MR, Munk K, et al. Impact of cardiovascular risk factors and medication use on the efficacy of remote ischaemic conditioning: post hoc subgroup analysis of a randomised controlled trial. BMJ Open 2015;5:e006923. doi:10.1136/bmjopen-2014006923

- Prepublication history for this paper is available online. To view these files please visit the journal online (http://dx.doi.org/10.1136/ bmjopen-2014-006923).

Received 15 October 2014 Revised 20 February 2015 Accepted 26 February 2015

CrossMark

\footnotetext{
${ }^{1}$ Department of Cardiology, Aarhus University Hospital, Aarhus N, Denmark ${ }^{2}$ Department of Clinical Epidemiology, Aarhus University Hospital, Aarhus $\mathrm{N}$, Denmark
}

Correspondence to Dr Astrid Drivsholm Sloth; astrid.drivsholm@clin.au.dk

\section{ABSTRACT}

Objectives: Remote ischaemic conditioning (RIC) promotes cardioprotection in patients undergoing primary percutaneous coronary intervention $(\mathrm{pPCl})$ for ST-elevation myocardial infarction (STEMI). The effect of RIC may be modified by cardiovascular risk factors and their medications. We examined whether cardiovascular risk factors, lipid and glucose levels, and medication use influenced the efficacy of RIC in patients with STEMI treated with $\mathrm{pPCl}$.

Design: Post hoc subgroup analysis of a single-centre randomised controlled trial.

Participants: A total of 139 patients with STEMI, randomised during ambulance transport to hospital for $\mathrm{pPCl}$ with $(\mathrm{n}=71)$ or without $(\mathrm{n}=68)$ RIC, met the trial criteria and achieved data for a myocardial salvage index (MSI).

Interventions: RIC was administered through intermittent arm ischaemia with four cycles of $5 \mathrm{~min}$ inflation and 5 min deflation of a blood pressure cuff.

Primary outcome measures: MSI, estimated by single-photon emission CT. We evaluated the efficacy of RIC on the MSI in patient subgroups of cardiovascular risk factors, lipid and glucose levels, and medication use.

Results: We found no significant difference in the efficacy of RIC in subgroups of cardiovascular risk factors, lipid and glucose levels, and medication use. However, point estimates indicated a reduced effect of RIC among smokers (median difference in MSI between RIC and control groups: $-0.02(95 \% \mathrm{Cl}-0.32$ to 0.28$)$ in smokers vs $0.25(95 \% \mathrm{Cl}$ 0.08 to 0.42 ) in non-smokers, $p$ value for interaction $=0.13$ ) and an increased effect of RIC in statin users (median difference in MSI between RIC and control groups: 0.34 $(95 \% \mathrm{Cl} 0.03$ to 0.65$)$ in statin users vs $0.09(95 \% \mathrm{Cl}$ -0.11 to 0.29 ) in non-statin users, $p$ value for interaction=0.19).

Conclusions: $\mathrm{RIC}$ as an adjunct to $\mathrm{pPCl}$ seems to improve MSI in our trial population of patients with STEMI regardless of most cardiovascular risk factors and their medications. Our post hoc finding on a limited sample size calls for further investigation in large-scale multicentre trials.

Trial registration number: NCT00435266.

\section{Strengths and limitations of this study}

- Cardiovascular risk factors and their medications may modify the response to cardioprotective therapies.

- This is the first examination of a potential modification by cardiovascular risk factors and medication use on the efficacy of remote ischaemic conditioning (RIC) as an adjunct to primary percutaneous coronary intervention in a randomised controlled trial.

- We found no significant difference in the efficacy of RIC in subgroups of cardiovascular risk factors and their medications. However, our analysis indicated a reduced effect of RIC among smokers and an increased effect of RIC in statin users.

- We used subgroup analysis on a limited sample size.

- Our post hoc analysis should be considered exploratory and calls for further investigation in large-scale multicentre trials.

\section{INTRODUCTION}

Remote ischaemic conditioning (RIC) consists of brief episodes of ischaemia administered distant from the heart to protect against myocardial ischaemia-reperfusion injury. ${ }^{1}$ The stimulus can be applied in a simple, low-cost manner using cycles of inflation and deflation of a blood pressure cuff placed around the upper arm. ${ }^{2}$ Despite the consistently positive effect of RIC found in animal studies, results have been ambiguous in the clinical setting of cardiovascular surgery and percutaneous coronary intervention. ${ }^{3}$ Most animal studies have been conducted using young and healthy animals. In the clinical setting, patients are older and often have a variety of comorbidities that may modify the effect of RIC and partially explain the bench-to-bedside discrepancy. ${ }^{5} 6$ 
Increasing evidence from animal studies suggests that the effect of ischaemic conditioning is attenuated by ageing, female gender, cardiovascular risk factors and comorbidities, such as diabetes mellitus, hypertension, left ventricular (LV) hypertrophy and hyperlipidaemia. ${ }^{56}$ In addition, several drugs frequently prescribed to patients with coronary artery disease, including statins, $\beta$-blockers and oral antidiabetics, may reduce the efficacy of ischaemic conditioning. ${ }^{5}{ }^{6}$

We previously showed that RIC performed in the prehospital setting before primary percutaneous coronary intervention (pPCI) increases myocardial salvage in patients with ST-elevation myocardial infarction (STEMI). ${ }^{7}$ The present analysis examined whether cardiovascular risk factors, lipid and glucose levels, and medication use modified the efficacy of RIC in patients with STEMI treated with pPCI.

\section{METHODS}

\section{Patients and study design}

This post hoc subgroup analysis included all patients in a single-centre randomised controlled trial, performed in Department of Cardiology, Aarhus University Hospital, Denmark. ${ }^{7}$ Patient selection and randomisation have been described in detail elsewhere. ${ }^{7}$ In brief, patients were enrolled in the study from February 2007 to November 2008. Criteria for inclusion were: (1) age $\geq 18$ years, (2) symptom duration of $\leq 12 \mathrm{~h}$ prior to admission and (3) ST-segment elevation $\geq 0.1 \mathrm{mV}$ in two or more contiguous ECG leads. ${ }^{7}$ Exclusion criteria were: (1) unconfirmed diagnosis during hospital admission, (2) history of previous myocardial infarction, (3) previous coronary artery bypass grafting (CABG) and (4) chest pain $>12 \mathrm{~h}$ before admission. ${ }^{7}$ RIC was initiated in the ambulance during transport to the interventional centre using intermittent arm ischaemia produced by four cycles of alternating $5 \mathrm{~min}$ inflation $(200 \mathrm{~mm} \mathrm{Hg}$ ) followed by 5 min deflation of a blood pressure cuff placed around the upper arm. ${ }^{7}$

\section{Cardiovascular risk factors, lipid and glucose levels, and medication use \\ Medical history}

On hospital arrival, information about age, gender, smoking status, height, weight, presence of diabetes mellitus, presence of hypertension and medication use, was entered in an electronic case report form for each patient. This information was obtained by interviewing the patient or relatives and subsequently validated by medical record review.

A 'smoker' was defined as an active smoker at the time of myocardial infarction. A 'non-smoker' was defined as a former smoker or never-smoker. Hypertension was defined as treatment with at least one antihypertensive drug at the time of myocardial infarction, with hypertension as the indication for the prescription. Diabetes mellitus was defined as diet-treated, oral-treated or insulin-treated diabetes mellitus at the time of myocardial infarction.

Treatment with $\beta$-blockers; ACE inhibitors; angiotensin II receptor blockers (ARBs); calcium channel blockers; and long-acting nitrates, statins, metformin, glimepiride and insulin, were defined as treatment with the drugs at the time of myocardial infarction.

\section{Echocardiography}

Echocardiography, performed at a median of $13 \mathrm{~h}$ after pPCI, permitted evaluation of LV mass. Echocardiography was performed by two investigators using a commercially available ultrasound system (Vivid 7; GE Healthcare) with a $3.5 \mathrm{MHz}$ phased array transducer (M4S). LV mass was calculated from M-mode measurements using the formula of Devereux and adjusted to body surface area. ${ }^{8}$ Patients were categorised as having LV hypertrophy when LV mass was at least moderately increased compared with reference range (LV mass $\geq 109 \mathrm{~g} / \mathrm{m}^{2}$ for women and $\geq 132 \mathrm{~g} / \mathrm{m}^{2}$ for men). ${ }^{8}$

\section{Biochemical variables}

Lipid and glucose values were obtained from the Clinical Laboratory Information System (LABKA). ${ }^{9}$ A non-fasting blood sample taken on hospital arrival was used to measure glucose $(\mathrm{mmol} / \mathrm{L})$. Total cholesterol $(\mathrm{mmol} / \mathrm{L})$, low-density lipoprotein (LDL) cholesterol $(\mathrm{mmol} / \mathrm{L})$ and glycated haemoglobin (HbAlc; \%) were measured using a morning fasting blood sample taken the day after admission. Plasma was used for all biochemical analyses.

\section{Outcome measure}

The primary outcome measure was the myocardial salvage index (MSI), estimated by single-photon emission CT (SPECT). The MSI, which quantifies the salvaged myocardium at risk, was calculated as ((area-at-risk (AAR)-final infarct size)/(AAR)). Before pPCI, ${ }^{99 m}$ TC-sestamibi was injected intravenously and AAR was measured by SPECT within $8 \mathrm{~h}$ after injection. We used the same method to quantify final infarct size 30 days after pPCI, with SPECT performed $1 \mathrm{~h}$ after injection of ${ }^{99 \mathrm{~m}} \mathrm{TC}$-sestamibi.

Trial staff members who collected and analysed the data were blinded to treatment assignment.

\section{Statistics}

The subgroup analysis was conducted on patients who met trial criteria and achieved data for MSI $(n=139)$. To examine effect modification, we computed stratumspecific differences in MSI between the RIC and control groups, and tested for interaction. Patients were stratified according to cardiovascular risk factors (age; gender; smoking status; body mass index; and presence/absence of diabetes mellitus, hypertension and LV hypertrophy), lipid and glucose levels (total cholesterol, LDL cholesterol, plasma glucose and HbA1c), and medication use ( $\beta$-blockers, ACE inhibitors, ARBs, calcium channel blockers and statins). Only a very limited number of 
patients were on antidiabetic medication and long-acting nitrates, so we did not stratify for these medications. Continuous variables were dichotomised using clinical cut-off values as follows: $\geq /<70$ years, $\geq /<25 \mathrm{~kg} / \mathrm{m}^{2}$ (body mass index), $\geq /<5.0 \mathrm{mmol} / \mathrm{L}$ (total cholesterol), $\geq /<3.0 \mathrm{mmol} / \mathrm{L}$ (LDL cholesterol), $\geq /<11.1 \mathrm{mmol} / \mathrm{L}$ (plasma glucose) and $\geq /<6.5 \%$ (HbA1c). Because the MSI did not follow a normal distribution, we used nonparametric quantile regression to calculate stratumspecific medians and stratum-specific median differences (with 95\% CIs), and to test for interaction between stratum-specific median differences. ${ }^{10}$ Non-parametric bootstrapping (1000 replications) computed all CIs and $\mathrm{p}$ values. Adjustment for multiple testing was not performed. A $p$ value $<0.05$ was considered statistically significant. Statistical analyses were made using STATA software (V.12, Stata Corp, College Station, Texas, USA).

\section{RESULTS}

The study flow chart is shown in figure 1. A total of 333 patients with suspected STEMI were randomly assigned to either RIC as an adjunct to pPCI $(n=166)$ or to standard treatment with pPCI alone $(n=167)$. Eighty-two patients were excluded during hospital admission, because they did not meet the trial criteria (34 with an unconfirmed diagnosis of STEMI, 41 with previous myocardial infarction, 4 with previous CABG and 3 with chest pain $>12 \mathrm{~h}$ before admission).

Paired AAR and infarct size evaluations from SPECT, used to calculate the primary outcome measure (MSI), were obtained for 140 patients. One patient was excluded from analysis, because the patient developed a large reinfarction between the first and second SPECT evaluations. This resulted in an unreliable MSI. The remaining 139 patients (71 patients in the RIC group and 68 patients in the control group) were eligible for further analysis.

Cardiovascular risk factors, lipid and glucose levels, and medication use did not differ substantially between the RIC and control groups, except for hypertension, which was more common in the RIC group (table 1). Procedural data did not differ between the RIC and control groups and have been published in detail elsewhere. ${ }^{7}$
Figure 1 Study flow chart. Grey boxes represent study population eligible for stratified analysis $(n=139)$. AAR, area-at-risk; ARBs, angiotensin II receptor blockers; FIS, final infarct size; $\mathrm{HbA1c}$, glycated haemoglobin; LDL, low-density lipoprotein; MSI, myocardial salvage index; $\mathrm{pPCl}$, primary percutaneous coronary intervention; RIC, remote ischaemic conditioning; STEMI, ST-elevation myocardial infarction.

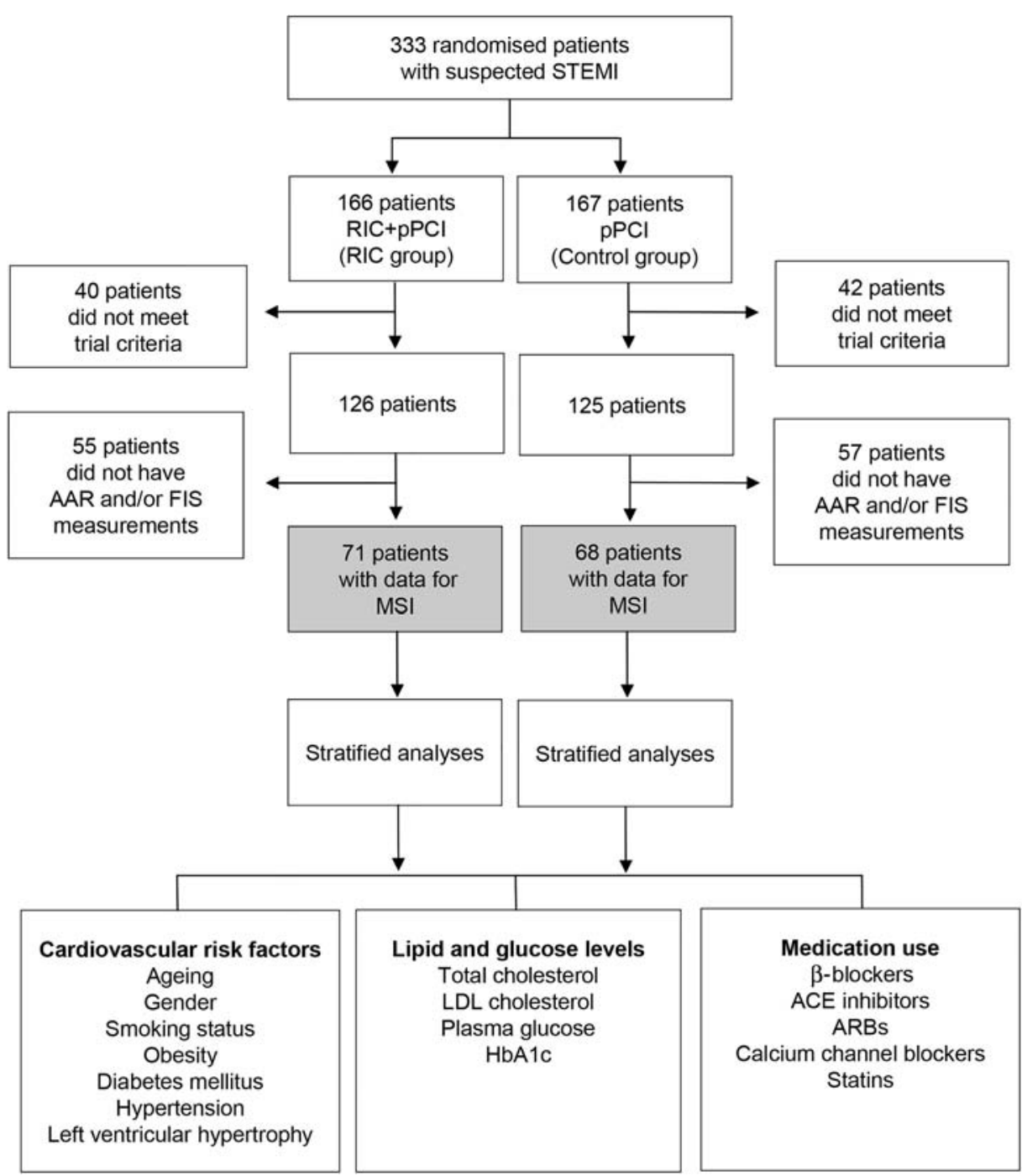


Table 1 Cardiovascular risk factors, lipid and glucose levels, and medication use for the study population eligible for stratified analysis

$\begin{array}{ll}\begin{array}{l}R I C+p P C l \\ (n=71)\end{array} & p P C l \\ (n=68)\end{array}$

\section{Cardiovascular risk factors}

Age (years)

Male

$63( \pm 11)$

$57(80 \%)$

$34(48 \%)$

$26( \pm 4)$

$6(8 \%)$

$32(45 \%)$

$7(10 \%)$

$62( \pm 11)$

$55(81 \%)$

$38(56 \%)$

$26( \pm 4)$

$8(12 \%)$

Diabetes mellitus

Hypertension

Left ventricular hypertrophy

Lipid and glucose levels

Total cholesterol $(\mathrm{mmol} / \mathrm{L})$

LDL cholesterol $(\mathrm{mmol} / \mathrm{L})$

Plasma glucose $(\mathrm{mmol} / \mathrm{L})$

HbA1c (\%)

Medication use

Metformin

Glimepiride

Insulin

$\beta$-blockers

ACE inhibitors

ARBs

Long-acting nitrates

Calcium channel blockers

Statins

Data are presented as mean (SD), median (IQR) or number (\%).

ARBs, angiotensin II receptor blockers; HbA1c, glycated

haemoglobin; LDL, low-density lipoprotein; pPCl, primary

percutaneous coronary intervention; RIC, remote ischaemic

conditioning.

Information about cardiovascular risk factors and medication use was available for $98-100 \%$ of the patients. An exception was LV mass, which was available for only $65 \%$ of the patients. Data on lipid and glucose levels were available for $72-85 \%$ of the patients (total cholesterol $85 \%$, LDL cholesterol $83 \%$, plasma glucose $75 \%$ and HbA1c 72\%). There was no difference in availability of these data between the two randomisation groups (table 2).

When we tested for interaction, there was no significant difference in the efficacy of RIC in subgroups of cardiovascular risk factors, lipid and glucose levels, and medication use (figure 2).

Based on the point estimates, the effect of RIC tended to be reduced in smokers (median difference in MSI between RIC and control groups was $-0.02 \quad(95 \%$ CI -0.32 to 0.28 ) in smokers vs 0.25 (95\% CI 0.08 to 0.42 ) in non-smokers, $p$ value for interaction $=0.13$ ), although CIs were wide. In other subgroups of cardiovascular risk factors, there was no difference in the point estimates, such as ageing (median difference in MSI between RIC and control groups was 0.14 (95\% CI -0.14 to 0.42$)$ in patients $\geq 70$ years vs 0.11 (95\% CI -0.11 to 0.33 ) in patients $<70$ years, $p$-value for interaction $=0.87$ ), gender (median difference in MSI between RIC and control groups was 0.33 (95\% CI 0.01 to 0.65 ) in females vs 0.21 $(95 \% \mathrm{CI}-0.03$ to 0.45$)$ in males, p-value for interaction $=0.56$ ) and hypertension (median difference in MSI between RIC and control groups was 0.16 (95\% CI -0.10 to 0.42$)$ in patients with hypertension vs 0.12 (95\% CI -0.15 to 0.39 ) in patients without hypertension, $\mathrm{p}$-value for interaction $=0.84$ ).

Regarding medication use, point estimates indicated an increased effect of RIC in statin users (median difference in MSI between RIC and control groups was 0.34 (95\% CI 0.03 to 0.65 ) in statin vs 0.09 (95\% CI -0.11 to 0.29 ) in non-statin users, $p$ value for interaction $=0.19$ ). No difference was seen in other subgroups of medication use, such as $\beta$-blocker treatment (median difference in MSI between RIC and control groups was 0.27 (95\% CI -0.05 to 0.59 ) in $\beta$-blocker vs 0.17 (95\% CI -0.03 to 0.37 ) in non- $\beta$-blocker users, $p$ value for interaction $=0.61$ ).

\section{DISCUSSION}

Our analysis did not demonstrate significant modification on the efficacy of RIC by cardiovascular risk factors and their medications in patients with STEMI undergoing pPCI. To our knowledge, this is the first investigation of a potential modification by cardiovascular risk factors and their medications on the efficacy of RIC as an adjunct to pPCI in a randomised controlled trial. Because the statistical power was limited, our study should be considered exploratory.

\section{Cardiovascular risk factors}

Although we did not find a significant modification by cardiovascular risk factors, our data indicated that the efficacy RIC might be reduced in smokers. The role of smoking in modulating cardioprotection by ischaemic conditioning strategies is unknown. The detrimental effects of smoking on the cardiovascular system, such as endothelial dysfunction, and activation of systemic inflammatory and prothrombotic processes, are mediated through a complex interaction of the several chemical compounds in tobacco smoke. ${ }^{11}$ Our findings suggest that smoking disrupts some of the transduction pathways involved in RIC and this might be a subject for further investigation in experimental and clinical human studies.

Ageing may modify the efficacy of RIC. ${ }^{5}$ The ageing heart is more susceptible to ischaemia-reperfusion injury through alternations in gene expression, signal transduction cascades and mitochondrial function. ${ }^{12}$ In an experimental human study, the relative increase in flowmediated vasodilation after RIC was higher in healthy elderly compared with young individuals. ${ }^{13}$ Additionally, a recent animal study reported that RIC did not protect against ischaemia-reperfusion injury and even caused deleterious effects in isolated newborn rabbit hearts, but reduced infarct size in adult rabbit hearts. ${ }^{14}$ Our intervention of four cycles with RIC seemed sufficient to 
Table 2 Stratum-specific medians and median differences in myocardial salvage index between RIC and control groups according to cardiovascular risk factors, lipid and glucose levels, and medication use

\begin{tabular}{|c|c|c|c|c|c|c|}
\hline & \multicolumn{2}{|c|}{ RIC+pPCI } & \multicolumn{2}{|c|}{$\mathrm{pPCl}$} & \multirow[b]{2}{*}{$\begin{array}{l}\text { Median } \\
\text { difference } \\
\text { (95\% Cl)† }\end{array}$} & \multirow[b]{2}{*}{$\begin{array}{l}\text { p-Value for } \\
\text { interaction }\end{array}$} \\
\hline & $\mathbf{N}^{*}$ & $\begin{array}{l}\text { Myocardial } \\
\text { salvage index } \\
\text { Median }(95 \% \mathrm{Cl})\end{array}$ & $\mathbf{N}$ & $\begin{array}{l}\text { Myocardial } \\
\text { salvage index } \\
\text { Median }(95 \% \mathrm{Cl})\end{array}$ & & \\
\hline Overall population & 71 & 0.75 (0.64 to 0.86$)$ & 68 & $0.56(0.42$ to 0.70$)$ & 0.19 (0.01 to 0.37$)$ & 0.03 \\
\hline \multicolumn{7}{|c|}{$\begin{array}{l}\text { Cardiovascular risk factors } \\
\text { Age (years) }\end{array}$} \\
\hline$\geq 70$ & 23 & 0.67 (0.43 to 0.91$)$ & 21 & 0.53 (0.38 to 0.68$)$ & $0.14(-0.14$ to 0.42$)$ & \multirow[t]{2}{*}{0.87} \\
\hline$<70$ & 48 & $0.76(0.66$ to 0.86$)$ & 47 & $0.65(0.46$ to 0.84$)$ & $0.11(-0.11$ to 0.33$)$ & \\
\hline \multicolumn{7}{|l|}{ Gender } \\
\hline Female & 14 & $0.93(0.70$ to 1.00$)$ & 13 & 0.60 (0.37 to 0.83$)$ & $0.33(0.01$ to 0.65$)$ & \multirow[t]{2}{*}{0.56} \\
\hline Male & 57 & 0.74 (0.56 to 0.92$)$ & 55 & $0.53(0.38$ to 0.68$)$ & $0.21(-0.03$ to 0.45$)$ & \\
\hline \multicolumn{7}{|l|}{ Smoking status } \\
\hline Smoker & 34 & 0.63 (0.44 to 0.82$)$ & 38 & 0.65 (0.42 to 0.88$)$ & $-0.02(-0.32$ to 0.28$)$ & \multirow[t]{2}{*}{0.13} \\
\hline Non-smoker & 37 & 0.80 (0.68 to 0.92$)$ & 29 & $0.55(0.42$ to 0.68$)$ & 0.25 (0.08 to 0.42$)$ & \\
\hline \multicolumn{7}{|c|}{ Body mass index $\left(\mathrm{kg} / \mathrm{m}^{2}\right)$} \\
\hline$\geq 25$ & 44 & $0.73(0.56$ to 0.90$)$ & 41 & 0.53 (0.37 to 0.69$)$ & $0.20(-0.03$ to 0.43$)$ & \multirow[t]{2}{*}{1.00} \\
\hline$<25$ & 27 & 0.75 (0.60 to 0.90$)$ & 25 & 0.55 (0.34 to 0.76$)$ & $0.20(-0.06$ to 0.46$)$ & \\
\hline \multicolumn{7}{|l|}{ Diabetes mellitus } \\
\hline Yes & 6 & 0.80 (0.62 to 0.98$)$ & 8 & 0.60 (0.36 to 0.84$)$ & $0.20(-0.10$ to 0.50$)$ & \multirow[t]{2}{*}{0.92} \\
\hline No & 65 & 0.74 (0.61 to 0.87$)$ & 60 & $0.56(0.40$ to 0.72$)$ & $0.18(-0.02$ to 0.38$)$ & \\
\hline \multicolumn{7}{|l|}{ Hypertension } \\
\hline Yes & 32 & 0.76 (0.65 to 0.87$)$ & 19 & 0.60 (0.37 to 0.83$)$ & $0.16(-0.10$ to 0.42$)$ & \multirow[t]{2}{*}{0.84} \\
\hline No & 39 & 0.67 (0.45 to 0.89$)$ & 49 & 0.55 (0.40 to 0.70$)$ & $0.12(-0.15$ to 0.39$)$ & \\
\hline \multicolumn{7}{|c|}{ Left ventricular hypertrophy } \\
\hline Yes & 7 & 0.50 (0.30 to 0.70$)$ & 8 & 0.48 (0.23 to 0.73$)$ & $0.02(-0.30$ to 0.34$)$ & \multirow[t]{2}{*}{0.35} \\
\hline No & 36 & 0.76 (0.62 to 0.90$)$ & 39 & 0.55 (0.37 to 0.73$)$ & $0.21(-0.02$ to 0.44$)$ & \\
\hline \multicolumn{7}{|c|}{ Lipid and glucose levels } \\
\hline \multicolumn{7}{|c|}{ Total cholesterol (mmol/L) } \\
\hline$\geq 5.0$ & 27 & 0.78 (0.68 to 0.88$)$ & 22 & 0.55 (0.35 to 0.75$)$ & $0.23(0.00$ to 0.46$)$ & 0.86 \\
\hline$<5.0$ & 34 & $0.76(0.57$ to 0.95$)$ & 35 & 0.50 (0.33 to 0.67$)$ & $0.26(0.01$ to 0.51$)$ & \\
\hline LDL cholesterol (m & $\mathrm{l} / \mathrm{L})$ & & & & & \\
\hline$\geq 3.0$ & 30 & 0.78 (0.67 to 0.89$)$ & 29 & 0.55 (0.40 to 0.70$)$ & 0.23 (0.05 to 0.41$)$ & 0.72 \\
\hline$<3.0$ & 29 & 0.79 (0.63 to 0.95$)$ & 28 & 0.50 (0.28 to 0.72$)$ & 0.29 (0.02 to 0.56$)$ & \\
\hline Plasma glucose (m & $\mathrm{l} / \mathrm{L})$ & & & & & \\
\hline$\geq 11.1$ & 6 & $0.73(0.44$ to 1.00$)$ & 7 & 0.48 (0.29 to 0.67$)$ & $0.25(-0.09$ to 0.59$)$ & 0.25 \\
\hline$<11.1$ & 46 & 0.67 (0.50 to 0.84$)$ & 45 & 0.68 (0.51 to 0.85$)$ & $0.01(-0.23$ to 0.25$)$ & \\
\hline $\mathrm{HbA1c}(\%)$ & & & & & & \\
\hline$\geq 6.5$ & 6 & 0.80 (0.60 to 1.00$)$ & 5 & $0.48(0.12$ to 0.84$)$ & $0.32(-0.09$ to 0.73$)$ & 0.73 \\
\hline$<6.5$ & 46 & 0.77 (0.65 to 0.89$)$ & 43 & 0.53 (0.39 to 0.67$)$ & 0.24 (0.06 to 0.42$)$ & \\
\hline $\begin{array}{l}\text { Medication use } \\
\beta \text {-blockers }\end{array}$ & & & & & & \\
\hline Yes & 11 & 0.87 (0.68 to 1.00$)$ & 10 & 0.60 (0.34 to 0.86$)$ & $0.27(-0.05$ to 0.59$)$ & 0.61 \\
\hline No & 58 & 0.70 (0.56 to 0.84$)$ & 57 & 0.53 (0.38 to 0.68$)$ & $0.17(-0.03$ to 0.37$)$ & \\
\hline ACE inhibitors & & & & & & \\
\hline Yes & 14 & 0.75 (0.63 to 0.87$)$ & 6 & 0.48 (0.13 to 0.83$)$ & $0.27(-0.10$ to 0.64$)$ & 0.69 \\
\hline No & 55 & $0.73(0.55$ to 0.91$)$ & 61 & 0.55 (0.41 to 0.69$)$ & $0.18(-0.05$ to 0.41$)$ & \\
\hline ARBs & & & & & & \\
\hline Yes & 10 & $0.58(0.41$ to 0.75$)$ & 5 & 0.48 (0.24 to 0.72$)$ & $0.10(-0.19$ to 0.39$)$ & 0.55 \\
\hline No & 59 & 0.78 (0.67 to 0.89$)$ & 62 & $0.56(0.42$ to 0.70$)$ & $0.22(0.04$ to 0.40$)$ & \\
\hline Calcium channel b & kers & & & & & \\
\hline Yes & 7 & 0.70 (0.42 to 0.98$)$ & 8 & 0.40 (0.00 to 0.84$)$ & $0.30(-0.21$ to 0.81$)$ & 0.73 \\
\hline No & 62 & 0.75 (0.60 to 0.90$)$ & 59 & 0.55 (0.41 to 0.69$)$ & $0.20(0.00$ to 0.40$)$ & \\
\hline Statins & & & & & & \\
\hline Yes & 12 & 0.80 (0.60 to 1.00$)$ & 12 & 0.46 (0.23 to 0.69$)$ & $0.34(0.03$ to 0.65$)$ & 0.19 \\
\hline No & 59 & 0.74 (0.61 to 0.87$)$ & 56 & 0.65 (0.50 to 0.80$)$ & $0.09(-0.11$ to 0.29$)$ & \\
\hline
\end{tabular}


Figure 2 Stratum-specific median differences in MSI between RIC and control groups according to cardiovascular risk factors, lipid and glucose levels, and medication use. Median difference $=$ calculated median difference in MSI between RIC and control groups using non-parametric quantile regression. Cls and $p$ values for interaction are computed with non-parametric bootstrapping (1000 replications). ARBs, angiotensin II receptor blockers; HbA1c, glycated haemoglobin; LDL, low-density lipoprotein; MSI, myocardial salvage index; $\mathrm{pPCl}$, primary percutaneous coronary intervention; RIC, remote ischaemic conditioning.
Median difference in MSI between RIC and control groups $(95 \% \mathrm{CI})$

P-value for interaction

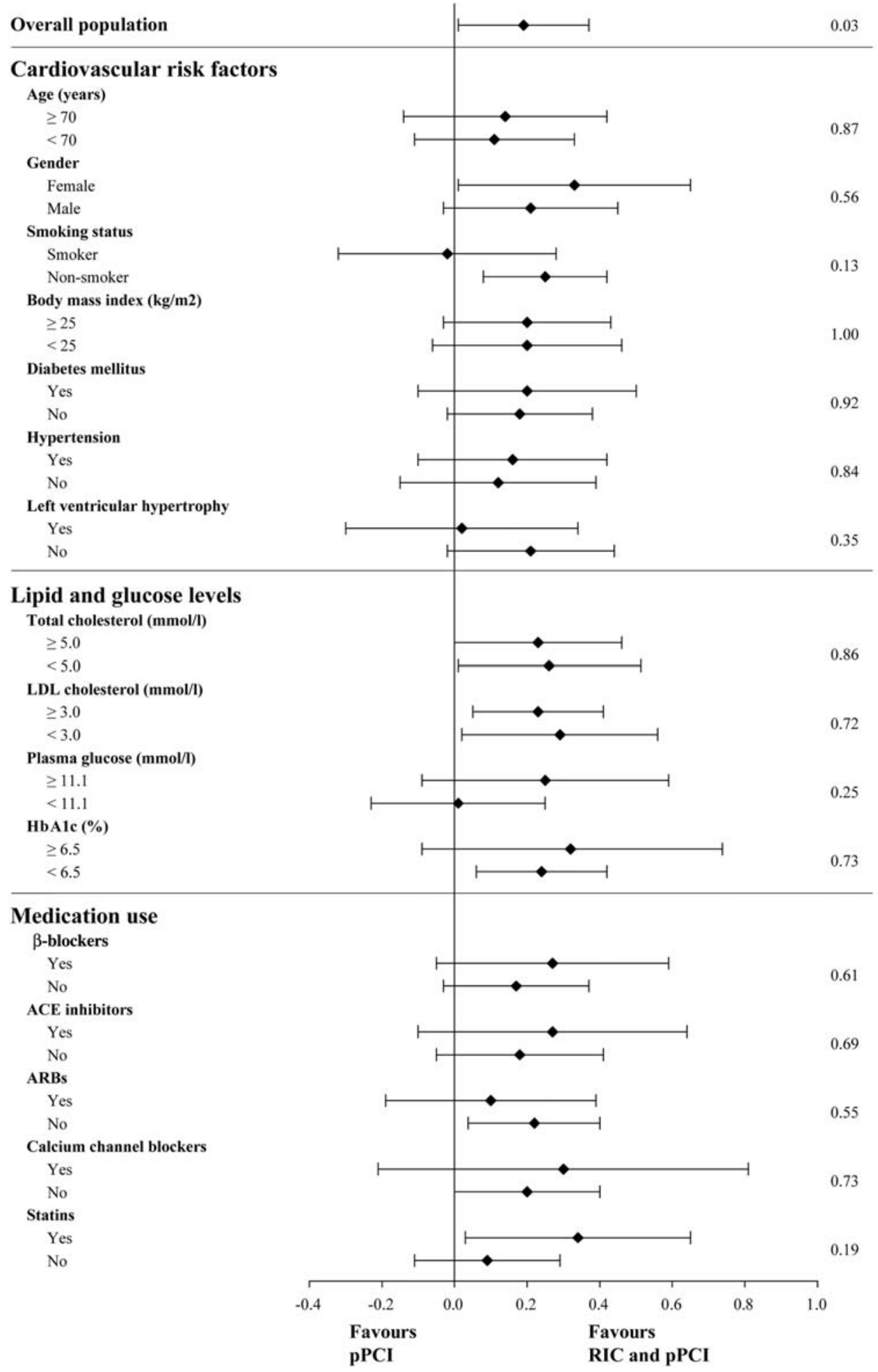

preserve the cardioprotective effect of RIC also in elderly patients aged over 70 years.

Female hearts have an increased natural resistance to ischaemia-reperfusion injury, although it decreases with ageing. ${ }^{5}$ Theoretically, this endogenous protection could restrict females from further exogenously activated cardioprotection by RIC. In our trial population of postmenopausal women, a cardioprotective effect of RIC seemed achievable. Our finding is supported by a meta-analysis of five randomised trials including 731 
patients undergoing elective PCI, where the efficacy of RIC in reducing peri-procedural myocardial infarction did not vary according to female gender. ${ }^{15}$

The number of patients with diabetes mellitus was limited and our analysis does not allow a conclusion about the modification of the efficacy of RIC in patients with diabetes mellitus. In a randomised trial including 200 elderly patients with diabetes mellitus undergoing elective PCI, RIC failed to show a significant reduction in peri-procedural myocardial injury. ${ }^{16}$ Two recent human and animal studies have shown the complexity of cardioprotection in diabetes mellitus. The first study demonstrated that the effect of RIC is dependent on preserved neural pathways in patients with diabetes mellitus. ${ }^{17}$ The second study showed that while alterations in mitochondrial metabolism in type 2 diabetic rats are associated with protection against ischaemia-reperfusion injury at diabetes onset, detrimental effects occur in later stages of the disease. ${ }^{18}$ Future large-scale human studies investigating the effect of RIC in patients with diabetes mellitus could improve our understanding by taking duration of diabetes mellitus and presence of diabetic neuropathy into account.

Until now, the interference of hypertension or LV hypertrophy with the ability to respond to RIC has only been examined in one animal study. Using a rat model of myocardial ischaemia, RIC seemed to protect myocardial contractile function in hypertrophied but surprisingly not normal rat hearts. ${ }^{19}$ In a human study investigating the effect of RIC on flow-mediated vasodilation in the elderly, the relative increase in flow-mediated vasodilation after RIC was higher in the healthy elderly compared with elderly patients with hypertension. ${ }^{13}$ Our subgroup analysis included very few patients with LV hypertrophy, but in patients with hypertension, the effect of RIC seemed preserved. However, it is important to note that we were unable to distinguish between patients with short-lasting and long-lasting hypertension.

\section{Medication use}

Little is known about the effect modification of statin use on RIC. ${ }^{5}$ Thus, we are the first to indicate a potential increased effect of RIC in statin users. Acute statin therapy seems to protect the myocardium directly from ischaemia-reperfusion injury, but the immediate cardioprotective effect may be attenuated in patients on persistent statin therapy. ${ }^{20-22}$ Whether RIC has a more pronounced effect in statin users deserves further investigation.

The cardioprotective effect of long-term treatment with $\beta$-blockers is well documented. ${ }^{23}$ However, it has been suggested that $\beta$-blocker use may interfere with other cardioprotective therapies. ${ }^{5}$ We found that the efficacy of RIC seemed to also be preserved in $\beta$-blocker users. In contrast, a meta-analysis of 15 clinical trials, including 1155 patients randomised to treatment with or without RIC before cardiac surgery, showed an attenuated effect of RIC in patients on perioperative $\beta$-blocker treatment. ${ }^{24}$

\section{Study limitations}

The predominant limitation of our study was the small sample size, resulting in low statistical power of the subgroup analysis to detect effect modification. Furthermore, the limited sample size did not allow multivariate analysis to control for residual confounding. Data on MSI were available only for the $56 \%$ of patients who met trial criteria. Lack of AAR evaluations was mainly responsible for missing MSI values, because SPECT was not available on a $24 \mathrm{~h}$ service basis. Between $72 \%$ and $85 \%$ of patients had lipid and glucose values measured, and only $65 \%$ of patients had echocardiographic M-mode measurements. However, because the missing data were assumed to be missing at random, systematic bias between treatment allocation and potential effect modifiers was unlikely. Another concern is that continuous variables were dichotomised using clinical cut-off points. Although dichotomising the variables introduced a potential risk of lost information, the sample size did not allow us to split continuous variables into more groups. Lipid concentrations undergo phasic changes during acute myocardial infarction. However, plasma lipids can be reliably assessed within $24 \mathrm{~h}$ after acute myocardial infarction as accomplished in our study. ${ }^{25}$ Finally, we used LV mass calculated from day 1 echocardiographic measurements to determine the presence of LV hypertrophy. The risk of an overestimation of LV hypertrophy due to acute myocardial oedema may be present. To compensate, we defined LV hypertrophy as at least moderately elevated LV mass.

\section{CONCLUSION}

RIC as an adjunct to pPCI seems to improve MSI in our trial population of patients with STEMI regardless of most cardiovascular risk factors and their medications. Our post hoc finding on a limited sample size calls for further investigation in large-scale multicentre studies.

Collaborators CONDI Investigators: M Bøttcher; AK Kaltoft; CJ Terkelsen; NH Andersen; TM Hansen; S Trautner; JF Lassen; EH Christiansen; LR Krusell; SD Kristensen; L Thuesen; SS Nielsen; M Rehling; TT Nielsen.

Contributors ADS had full access to all data in the study and takes responsibility for the integrity of the data and accuracy of the data analysis. HEB, ADS, MRS and HTS were involved in study concept and design. Data collection: (1) ADS contributed to medical history and blood values, (2) KM and NH Andersen contributed to echocardiography. ADS and LP were involved in statistical analyses. ADS, MRS, KM, HEB, MS, LP and HTS were involved in interpretation of data. ADS wrote the paper. MRS, KM, HEB, MS LP and HTS were involved in critical revision of the paper.

Funding This work was supported by The Danish Council for Independent Research (11-108354), The Danish Council for Strategic Research (11-115818) and Fondation Leducq (06CVD).

Competing interests MRS and HEB are shareholders in CellAegis.

Ethics approval This study was approved by the Regional Ethics Committee and the Danish Data Protection Agency.

Provenance and peer review Not commissioned; externally peer reviewed.

Data sharing statement Raw data and statistical coding are available from the corresponding author at astrid.drivsholm@clin.au.dk. 
Open Access This is an Open Access article distributed in accordance with the Creative Commons Attribution Non Commercial (CC BY-NC 4.0) license, which permits others to distribute, remix, adapt, build upon this work noncommercially, and license their derivative works on different terms, provided the original work is properly cited and the use is non-commercial. See: http:// creativecommons.org/licenses/by-nc/4.0/

\section{REFERENCES}

1. Przyklenk K, Bauer B, Ovize M, et al. Regional ischemic 'preconditioning' protects remote virgin myocardium from subsequent sustained coronary occlusion. Circulation 1993:87:893-9.

2. Kharbanda RK, Mortensen UM, White PA, et al. Transient limb ischemia induces remote ischemic preconditioning in vivo. Circulation 2002:106:2881-3.

3. Brevoord D, Kranke P, Kuijpers M, et al. Remote ischemic conditioning to protect against ischemia-reperfusion injury: a systematic review and meta-analysis. PLOS ONE 2012;7:e42179.

4. Heusch G. Cardioprotection: chances and challenges of its translation to the clinic. Lancet 2013;381:166-75.

5. Ferdinandy P, Hausenloy DJ, Heusch G, et al. Interaction of risk factors, comorbidities, and comedications with ischemia/reperfusion injury and cardioprotection by preconditioning, postconditioning, and remote conditioning. Pharmacol Rev 2014;66:1142-74.

6. McCafferty K, Forbes S, Thiemermann C, et al. The challenge of translating ischemic conditioning from animal models to humans: the role of comorbidities. Dis Model Mech 2014;7:1321-33.

7. Botker HE, Kharbanda R, Schmidt MR, et al. Remote ischaemic conditioning before hospital admission, as a complement to angioplasty, and effect on myocardial salvage in patients with acute myocardial infarction: a randomised trial. Lancet 2010;375:727-34.

8. Lang RM, Bierig M, Devereux RB, et al. Recommendations for chamber quantification. Eur J Echocardiogr 2006;7:79-108.

9. Grann AF, Erichsen R, Nielsen AG, et al. Existing data sources for clinical epidemiology: the clinical laboratory information system (LABKA) research database at Aarhus University, Denmark. Clin Epidemiol 2011;3:133-8.

10. Gould W. sg11.1: Quantile regression with bootstrapped standard erros. Stata Technical Bulletin 9 1992:19-21.

11. Messner B, Bernhard D. Smoking and cardiovascular disease: mechanisms of endothelial dysfunction and early atherogenesis. Arterioscler Thromb Vasc Biol 2014;34:509-15.

12. Boengler K, Schulz R, Heusch G. Loss of cardioprotection with ageing. Cardiovasc Res 2009;83:247-61.

13. Moro L, Pedone C, Mondi A, et al. Effect of local and remote ischemic preconditioning on endothelial function in young people and healthy or hypertensive elderly people. Atherosclerosis 2011;219:750-2.
14. Schmidt MR, Stottrup NB, Michelsen MM, et al. Remote ischemic preconditioning impairs ventricular function and increases infarct size after prolonged ischemia in the isolated neonatal rabbit heart. $J$ Thorac Cardiovasc Surg 2014;147:1049-55.

15. D'Ascenzo F, Moretti C, Omede P, et al. Cardiac remote ischaemic preconditioning reduces periprocedural myocardial infarction for patients undergoing percutaneous coronary interventions: a meta-analysis of randomised clinical trials. Eurolntervention 2014;9:1463-71.

16. $\mathrm{XuX}$, Zhou $\mathrm{Y}$, Luo $\mathrm{S}$, et al. Effect of remote ischemic preconditioning in the elderly patients with coronary artery disease with diabetes mellitus undergoing elective drug-eluting stent implantation. Angiology 2014;65:660-6.

17. Jensen RV, Stottrup NB, Kristiansen SB, et al. Release of a humoral circulating cardioprotective factor by remote ischemic preconditioning is dependent on preserved neural pathways in diabetic patients. Basic Res Cardiol 2012;107:285.

18. Povlsen JA, Lofgren B, Dalgas C, et al. Protection against myocardial ischemia-reperfusion injury at onset of type 2 diabetes in Zucker diabetic fatty rats is associated with altered glucose oxidation. PLoS ONE 2013;8:e64093.

19. Voucharas C, Lazou A, Triposkiadis F, et al. Remote preconditioning in normal and hypertrophic rat hearts. J Cardiothorac Surg $2011 ; 6: 34$

20. Ludman A, Venugopal V, Yellon DM, et al. Statins and cardioprotection-more than just lipid lowering? Pharmacol Ther 2009;122:30-43.

21. Mensah K, Mocanu MM, Yellon DM. Failure to protect the myocardium against ischemia/reperfusion injury after chronic atorvastatin treatment is recaptured by acute atorvastatin treatment: a potential role for phosphatase and tensin homolog deleted on chromosome ten? J Am Coll Cardiol 2005;45: 1287-91.

22. Ludman AJ, Hausenloy DJ, Babu G, et al. Failure to recapture cardioprotection with high-dose atorvastatin in coronary artery bypass surgery: a randomised controlled trial. Basic Res Cardiol 2011:106:1387-95.

23. Yang JH, Hahn JY, Song YB, et al. Association of beta-blocker therapy at discharge with clinical outcomes in patients with ST-segment elevation myocardial infarction undergoing primary percutaneous coronary intervention. JACC Cardiovasc Interv 2014;7:592-601.

24. Zhou C, Liu Y, Yao Y, et al. Beta-blockers and volatile anesthetics may attenuate cardioprotection by remote preconditioning in adult cardiac surgery: a meta-analysis of 15 randomized trials. $J$ Cardiothorac Vasc Anesth 2013;27:305-11.

25. Ahnve S, Angelin B, Edhag O, et al. Early determination of serum lipids and apolipoproteins in acute myocardial infarction: possibility for immediate intervention. J Intern Med 1989;226:297-301. 